\title{
A $14,000-M_{\mathrm{r}}$ Envelope Protein of Vaccinia Virus Is Involved in Cell Fusion and Forms Covalently Linked Trimers $\dagger$
}

\author{
JOSE F. RODRIGUEZ, EDUARDO PAEZ, AND MARIANO ESTEBAN* \\ Departments of Biochemistry, Microbiology, and Immunology, State University of New York Health Science Center, \\ Brooklyn, New York 11203
}

Received 15 August 1986/Accepted 28 October 1986

\begin{abstract}
A monoclonal antibody, MAbC3, that reacts with a 14,000-molecular-weight envelope protein (14K protein) of vaccinia virus completely inhibited virus-induced cell fusion during infection. Immunoblot and immunofluorescence studies revealed that the $14 \mathrm{~K}$ protein was synthesized at about 6 to $7 \mathrm{~h}$ postinfection and transported from the cytoplasm to the cell surface. Synthesis and transport of the 14K protein during infection occurred in the presence of rifampin, an inhibitor of virus maturation. One- and two-dimensional gel electrophoretic analyses demonstrated that the $14 \mathrm{~K}$ protein forms largely trimers $(42 \mathrm{~K})$ that are covalently linked by disulfide bonds. The facts that MAbC3 prevents virus uncoating and blocks virus-induced cell fusion but does not prevent virus attachment to cells and the $14 \mathrm{~K}$ envelope protein forms trimers all suggest that this protein plays major role in virus penetration.
\end{abstract}

\begin{abstract}
Vaccinia virus, a member of the genus Orthopoxvirus, is one of the largest and most complex animal viruses. The large 187-kilobase double-stranded genome codes for over 200 genes which are involved in viral transcription, DNA replication, and morphogenesis (6). About 100 polypeptides are associated with the virion (8), and approximately 279 polypeptides are induced during virus infection (3). The biological activities and functions of most of these proteins are presently unknown. In particular, it has not been firmly established which polypeptides are involved in the early interactions with the host cell which lead to entry of the virus, although it is believed that such proteins are localized in the outer envelope. Based on studies with specific neutralizing antibodies, Stern and Dales (1976) have proposed that an abundant 54,000-molecular-weight surface tubule protein ( $54 \mathrm{~K}$ protein) may mediate entry of the virus. On the other hand, Ichihashi and Oie (1980) have obtained biochemical evidence that viral binding occurs through a $37 \mathrm{~K}$ envelope component but subsequent penetration of the virus requires the activity of a second, lower-molecular-weight species also found in the envelope. Recent studies indicate that viral binding might occur through an epidermal growth factor receptor (7), but since vaccinia virus can infect cells that lack the epidermal growth factor receptor (26), it proves that this is not the main route of entry of the virus to the cells. Based on electron microscopic and biochemical analyses, it has been inferred that one step in virus penetration is cell fusion (1, 5, R. A. Janeczko, J. F. Rodriguez, and M. Esteban, Arch. Virol., in press). Although there is no clear agreement on the specific proteins involved in viral entry, the above studies indicate that they are localized in the outer envelope and that viral binding and subsequent entry can be dissociated as separate events in what is apparently a multistep process.
\end{abstract}

As a way to study the structure and function of viral proteins that might have a direct role in virus attachment and cell fusion, we have prepared hybridomas secreting monoclonal antibodies directed against structural proteins of vaccinia virus (23). In the present study, we demonstrated

\footnotetext{
* Corresponding author.

$\dagger$ This paper is dedicated to the memory of John A. Holowczak.
}

that a $14 \mathrm{~K}$ envelope protein of vaccinia virus is involved in cell fusion. We also showed that vaccinia virus infection induces transport of this protein from the cytoplasm to the cell surface. Finally, we determined that the $14 \mathrm{~K}$ protein forms trimers in the surface of the virions.

\section{MATERIALS AND METHODS}

Cells and viruses. Mouse $\mathrm{L}$ cells and African green monkey kidney cells (BSC-40) were grown as monolayer cultures in Dulbecco modified medium containing $10 \%$ newborn calf serum and antibiotics. Stocks of vaccinia virus strain WR and mutant 87-4 were prepared by infecting BSC-40 cells at a multiplicity of 0.1 PFU per cell, and virus was purified by sucrose gradient centrifugation as previously described $(9$, 13). The virus mutant 87-4 was obtained from interferontreated Friend erythroleukemia cells persistently infected with the WR strain of vaccinia virus after 87 passages $(19$, 20) and was selected because of its ability to cause extensive cell fusion to infected cultures. The particle-to-PFU ratio was about 30:1 for wild-type virus and $46: 1$ for the mutant virus when titers were determined on BSC-40 cells.

Generation of MAbs. Monoclonal antibodies (MAbs) were generated as described by Rodriguez et al. (23). Three MAbs, MAbC3, MAbB11, and MAbF11, recognized a $14 \mathrm{~K}$ envelope protein and were used throughout. The properties of these MAbs have been described previously (23).

Immunoblotting. Protein from purified virions (20 to $40 \mu \mathrm{g})$ or cell extracts $(60 \mu \mathrm{g})$ was applied to each well and fractionated on $12 \%$ sodium dodecyl sulfate (SDS)polyacrylamide gels. The proteins were transferred to nitrocellulose, and immunoblots were developed as described previously (23), except that $5 \%$ blotto (nonfat dry milk) was used instead of fetal calf serum. Virions and cells were disrupted by boiling for $3 \mathrm{~min}$ in sample buffer containing 30 $\mathrm{mM}$ Tris-hydrochloride ( $\mathrm{pH} \mathrm{6.8),2 \%} \mathrm{SDS,} 5 \%$ glycerol, and $0.012 \%$ bromophenol blue in the absence or presence (50 $\mathrm{mM}$ ) of the reducing agent dithiothreitol (DTT).

Immunofluorescence. Cells growing in cover slips (24 wells) were infected with vaccinia virus, and at various times postinfection cells were washed 3 times with phosphatebuffered saline (PBS) and fixed under conditions that made the cells nonpermeable ( $4 \%$ formaldehyde- $0.1 \%$ glutaralde- 
a
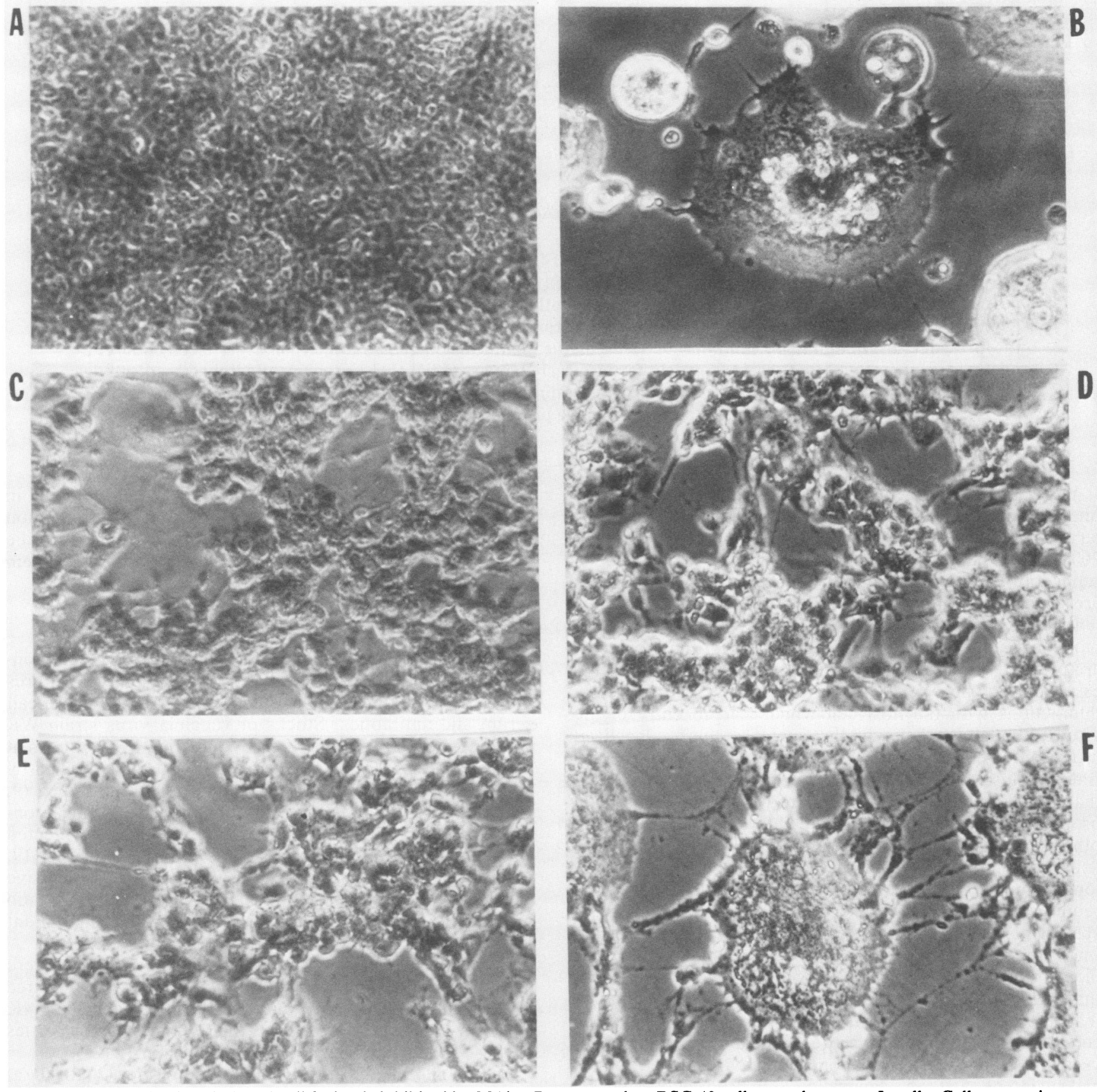

FIG. 1. Vaccinia virus-induced cell fusion is inhibited by MAbs. Part a, monkey BSC-40 cells; part b, mouse L cells. Cells grown in cover slips (24 tissue culture wells) were infected with 1 PFU of vaccinia virus mutant 87-4 per cell. After $1 \mathrm{~h}$ of virus adsorption, inoculum was removed by washing, and medium containing $2 \%$ newborn calf serum and MAbs as ascites was added to the cultures. The extent of cell fusion was monitored during infection. By visual inspection, fusion began at about $6 \mathrm{~h}$. Cells were photographed under a phase-contrast microscope, and the results obtained at $24 \mathrm{~h}$ are shown at the same magnification. Part a (panels): A, uninfected cells; B, infected cells; C, infected cells treated with MAbC3 diluted 1:50, D, infected cells treated with MAbB11 diluted 1:50; E, infected cells treated with MAbC3 and MAbB11 diluted 1:100 each; F, infected cells treated with MAbB6 diluted 1:50, which is specific for a 37K core-associated protein (unpublished data). Part b, (panels): A, uninfected cells; B, infected cells; C, infected cells treated with MAbC3 diluted 1:100; D, infected cells treated with MAbF11 diluted 1:100.

hyde in PBS at $4^{\circ} \mathrm{C}$ for $45 \mathrm{~min}$ ) or permeable (cold acetone at room temperature for $15 \mathrm{~min}$ ). Subsequent treatments were carried out at room temperature. Cells were washed 3 times with PBS, $1 \%$ bovine serum albumin in PBS was added for 1 $\mathrm{h}$ and then removed, and the cells were incubated for $60 \mathrm{~min}$ with MAbC3, MAbB11, or MAbF11 diluted in $1 \%$ bovine serum albumin. Cells were washed 5 times with PBS and then incubated for $30 \mathrm{~min}$ with affinity-purified goat antimouse immunoglobulin $\mathrm{G}$ conjugated with Rhodamine (Cooper Biomedical, Inc., West Chester, Pa.) at a 1:10 dilution in 

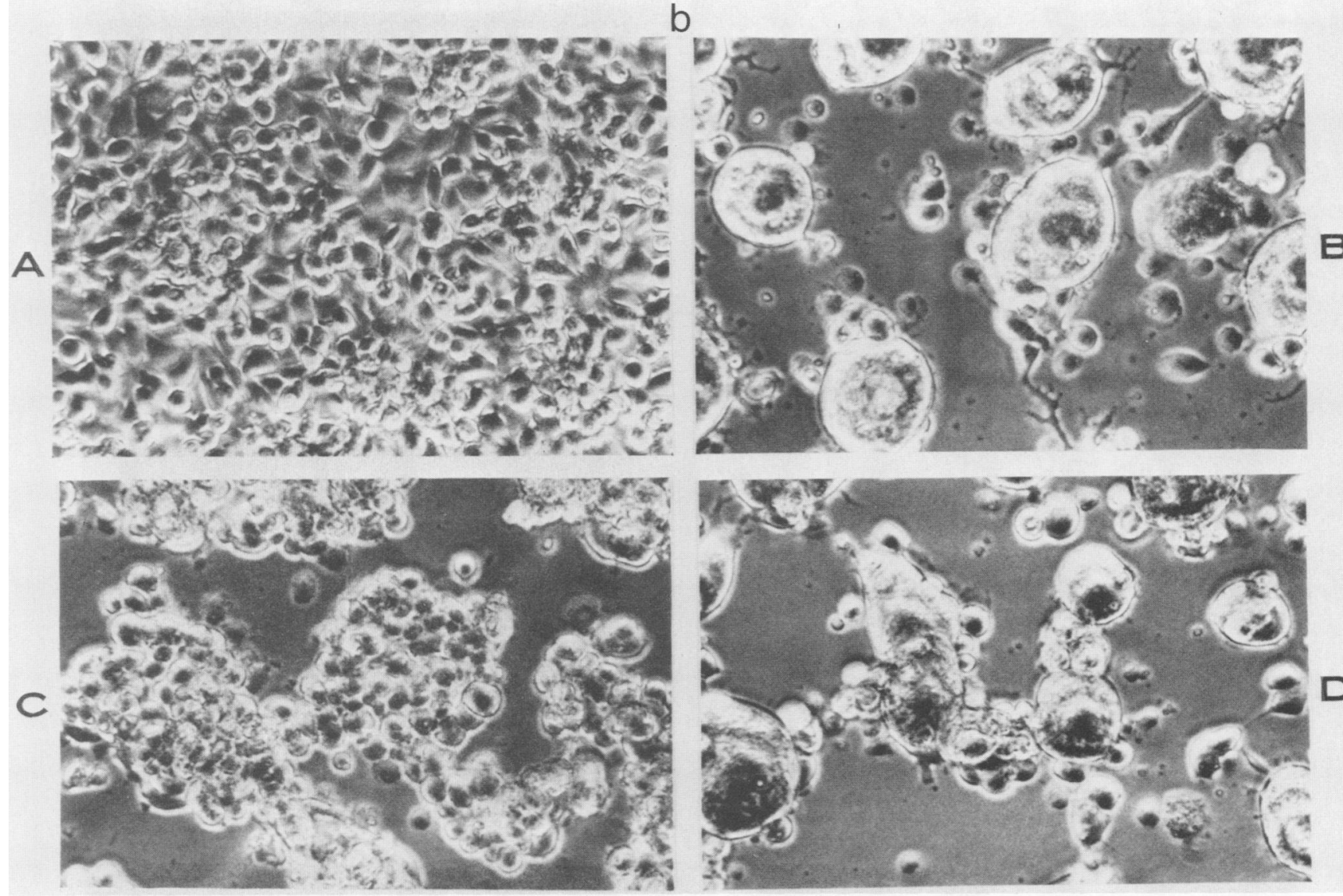

FIG. 1-Continued.

$1 \%$ bovine serum albumin. Cells were washed 5 times with PBS, cover slips were mounted in glycerol-PBS (1:1 vol/vol) on a microscope slide, excess buffer was removed, and the cover slips were sealed with nail polish. Cells were visualized and photographed in a Zeiss fluorescence microscope.

\section{RESULTS}

The 14K envelope protein of vaccinia virus is involved in cell fusion. We have previously described three MAbs (MAbC3, MAbB11, and MAbF11) that recognize different epitopes within the $14 \mathrm{~K}$ envelope protein of vaccinia virus and were able, to different extents, to block virus uncoating but not virus attachment to infected cells (23). We have also reported that the low-pH endocytic pathway is not important for vaccinia virus entry, but fusion of the virus with the plasma membrane might play a major role in virus penetration (Janeczko et al., in press). As an extension of these studies, here we wanted to determine whether the $14 \mathrm{~K}$ protein might be required for virus penetration acting at one step subsequent to virus attachment. To achieve this aim, we used a mutant of vaccinia virus that causes extensive cell fusion during infection. Cells were infected with vaccinia virus mutant $87-4$, and $1 \mathrm{~h}$ after virus adsorption, cells were treated with various dilutions of MAbC3, MAbB11, or MAbF11 as ascites. At $24 \mathrm{~h}$ postinfection, cells of either monkey or mouse origin were visualized for syncytium formation by phase-contrast microscopy. Typical results are shown in Fig. 1a. The most striking observation was that, in infected cells treated with MAbC3 (Fig. 1a, panel C),
MAbB11 (Fig. 1a, panel D), a mixture of the two MAbs (Fig. $1 \mathrm{a}$, panel E), or an unrelated MAb (Fig. 1a, panel F), the phenomenon of virus-induced cell fusion (Fig. 1a, panel B) was completely blocked only by the two MAbs that recognize epitopes of the vaccinia $14 \mathrm{~K}$ protein. However, when infected cells were treated with MAbF11 (Fig. 1b), virusinduced cell fusion was not blocked by this MAb (Fig. 1b, panel D). The extent of inhibition of cell fusion was greater for MAbC3, producing $50 \%$ inhibition at a dilution of $10^{-3}$, as opposed to $10^{-2}$ for MAbB11. This is in line with our previous finding that $\mathrm{MAbC} 3$ possesses the strongest neutralizing activity and impairment of virus uncoating (23). Because of the specificity of these MAbs (23), we concluded that the $14 \mathrm{~K}$ envelope protein of vaccinia virus is involved in cell fusion.

The 14K envelope protein of vaccinia virus is expressed on the cell surface. Inhibition of virus-induced cell fusion by MAbs (Fig. 1) suggested that the $14 \mathrm{~K}$ protein is transported from the cytoplasmic site of synthesis to the cell surface during infection. Thus, we visualized the cellular localization of the $14 \mathrm{~K}$ protein by indirect immunofluorescence. To evaluate the distribution of the $14 \mathrm{~K}$ protein between the cell surface and the cytoplasm, we used both nonpermeabilized and permeabilized cells, untreated or treated with MAbC3 (Fig. 2). Whereas there was no fluorescence staining for uninfected nonpermeabilized cells (Fig. 2A and B), strong staining was observed in both virus-infected cells with syncytium formation (Fig. 2C and D) and virus-infected cells in which cell fusion was prevented by MAbC3 (Fig. 2E and $F)$. If an $M A b$ reactive against a $37 \mathrm{~K}$ core protein of vaccinia 

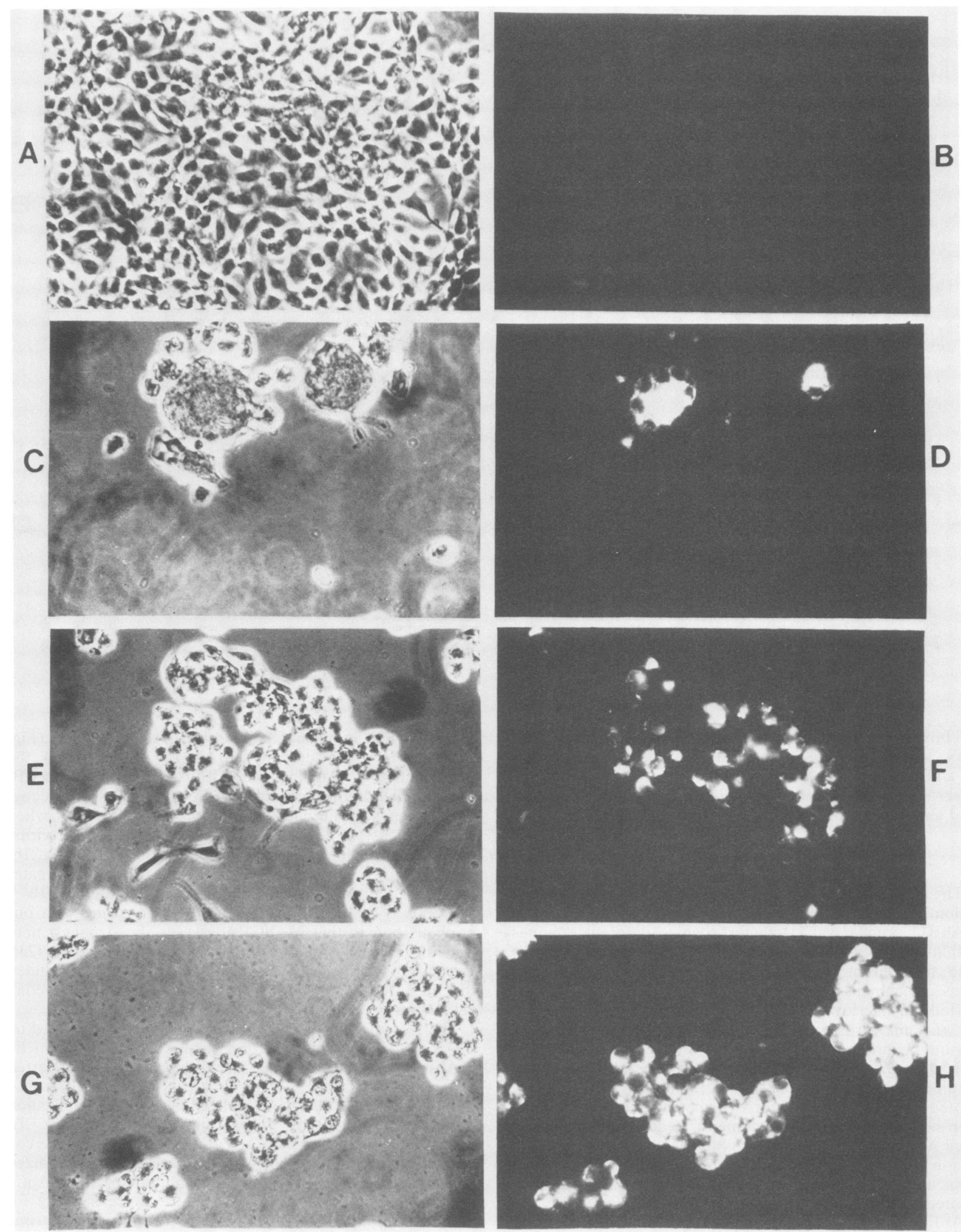

FIG. 2. Localization of $14 \mathrm{~K}$ envelope proterns in vaccinia virus-infected cells with MAbC3. Conditions for virus infection of mouse $\mathrm{L}$ cells with mutant 87-4 were as in Fig. 1. At 24 h postinfection, cells were fixed under nonpermeabilized (panels A to F) or permeabilized (panels $\mathrm{G}$ and $\mathrm{H}$ ) conditions and treated with $\mathrm{MAbC} 3$ at a 1:50 dilution, and the cover slips were processed for indirect immunofluorescence staining as described in Materials and Methods. Photographs represent phase-contrast and fluorescent images of the same cells. Panels: A and B, uninfected cells; $C$ and $D$, infected cells; $E$ and F, infected cells treated with MAbC3; $\mathrm{G}$ and $\mathrm{H}$, permeabilized infected cells treated with $\mathrm{MAbC3}$. 
virus was used instead of MAbC3, staining was not observed in nonpermeabilized infected cells (data not shown). After permeabilization, the intensity of staining increased, as seen in infected cells treated with MAbC3 (Fig. 2G and H). Inspection of the cells shown in Fig. 2 revealed that staining was not within the nucleus but was confined to the cytoplasm and the cell surface. Thus, we concluded that during infection the $14 \mathrm{~K}$ envelope protein of vaccinia virus is expressed on the cell surface and accumulates in the cytoplasm of the cell.

Vaccinia virus-induced cell fusion is not caused by virus release from the cells. It is possible that some staining of the $14 \mathrm{~K}$ protein on the cell surface represents mature virus that is released from the cells late in infection and remains cell associated. Thus, to eliminate the possible contribution of mature virus to cell surface staining, cells were infected with the mutant in the presence of rifampin, an inhibitor of virus maturation $(10,18)$. The fluorescence staining of nonpermeabilized infected cells is shown in Fig. 3A. It was clear that intense immunofluorescence was observed throughout the cell surface and that virus-induced cell fusion does not require virus maturation.

To assure that rifampin had no effect on the relative amount of the $14 \mathrm{~K}$ protein during infection, we measured the intracellular concentrations of the $14 \mathrm{~K}$ protein by immunoblot analysis. Rifampin did not alter the levels nor the size of the $14 \mathrm{~K}$ protein during infection (Fig. 3C).

We concluded that synthesis and expression of the $14 \mathrm{~K}$ protein on the cell surface of vaccinia virus-infected cells occurs independently of virus maturation.

Synthesis and transport of the $14 \mathrm{~K}$ protein occurs late in virus infection. To define the time course of synthesis for the

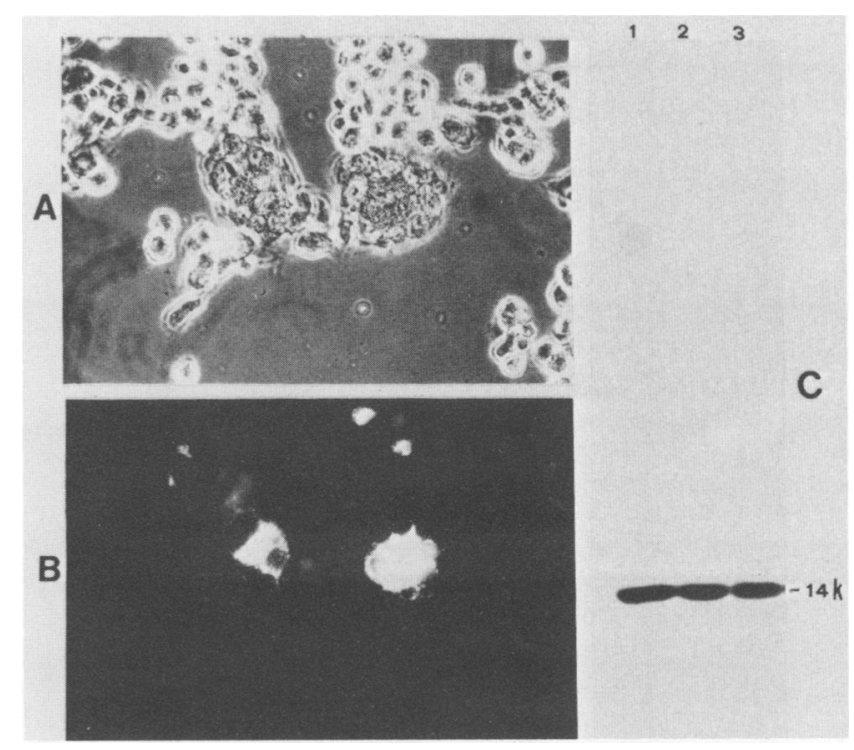

FIG. 3. Localization and accumulation of the $14 \mathrm{~K}$ envelope protein in vaccinia virus-infected cells in the presence of rifampin. Mouse L cells were infected, as for Fig. 1, with mutant 87-4 in the presence of $100 \mu \mathrm{g}$ of rifampin per $\mathrm{ml}$ and processed for indirect immunofluorescence or immunoblotting as described in Materials and Methods. Phase-contrast (panel A) and immunofluorescence (panel B) staining of drug-treated cells at $24 \mathrm{~h}$ postinfection are shown. Panel $\mathrm{C}$ shows immunoperoxidase staining of cell extracts fractionated by $12 \%$ SDS-polyacrylamide gel electrophoresis and prepared from (lanes): 1 , infected cells at $8 \mathrm{~h}$; 2 , infected cells treated with rifampin for $6 \mathrm{~h}$ and then maintained in the absence of the drug for $2 \mathrm{~h} ; 3$, infected cells treated with rifampin for $8 \mathrm{~h}$.

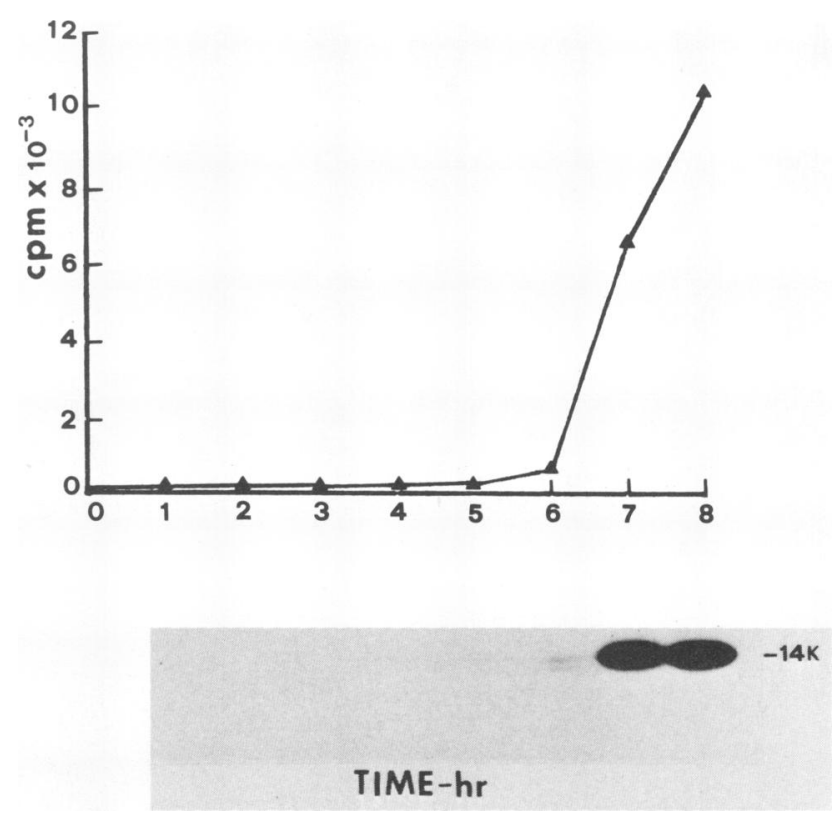

FIG. 4. Production (versus time) of the $14 \mathrm{~K}$ envelope protein in vaccinia virus-infected cells. Mouse $L$ cells grown in Limbro culture dishes $(6$ by $6 \mathrm{~cm})$ were infected with wild-type vaccinia virus $(5$ PFU per cell). At various times postinfection, cells were collected, lysed, and fractionated on a $12 \%$ polyacrylamide gel. The gel was blotted, reacted with MAbC 3 and then ${ }^{125}$ I-protein A, and exposed to XAR-5 film for autoradiography. The labeled band was cut from the gel, and the radioactivity was counted in a gamma counter. The extent of radioactivity incorporated in the $14 \mathrm{~K}$ band and the corresponding autoradiogram are shown at various times postinfection.

$14 \mathrm{~K}$ envelope protein during virus infection, we carried out immunoblot and immunofluorescence analyses. Cells were infected with vaccinia virus, and at various times postinfection cell extracts were prepared and run on SDS-polyacrylamide gel electrophoresis. The proteins were transferred to nitrocellulose paper, the paper was reacted with MAbC3, and the antigen-antibody complex was visualized with ${ }^{125}$ I-protein A after autoradiography. The labeled $14 \mathrm{~K}$ protein band was cut from the gel, and the radioactivity was counted. The results are shown in Fig. 4 for wild-type virus, although similar results were obtained with the mutant virus. It was clear that synthesis of the $14 \mathrm{~K}$ protein began at about $6 \mathrm{~h}$ and then rose sharply at about $7 \mathrm{~h}$ postinfection. Synthesis of the $14 \mathrm{~K}$ protein was prevented in infected cells treated with an inhibitor of DNA synthesis such as hydroxyurea (data not shown). To document whether synthesis of the $14 \mathrm{~K}$ protein parallels its expression on the cell surface, we carried out immunofluorescence analysis at various times postinfection. The results of nonpermeabilized infected cells reacted with MAbC3 are shown in Fig. 5. Whereas poor staining was seen on the cell surface at $4 \mathrm{~h}$ postinfection, marked staining was observed at $8 \mathrm{~h}$ postinfection. We concluded that the $14 \mathrm{~K}$ protein of vaccinia virus is synthesized at late times postinfection and transported to the cell surface with similar kinetics.

The 14K envelope protein of vaccinia virus forms trimers held by disulfide bonds. The ability of MAbs to block virus-induced cell fusion and the fact that the $14 \mathrm{~K}$ protein elicits neutralizing antibodies suggested that the native configuration of this low-molecular-weight protein is more complex than a single polypeptide chain. Since it is known that a 

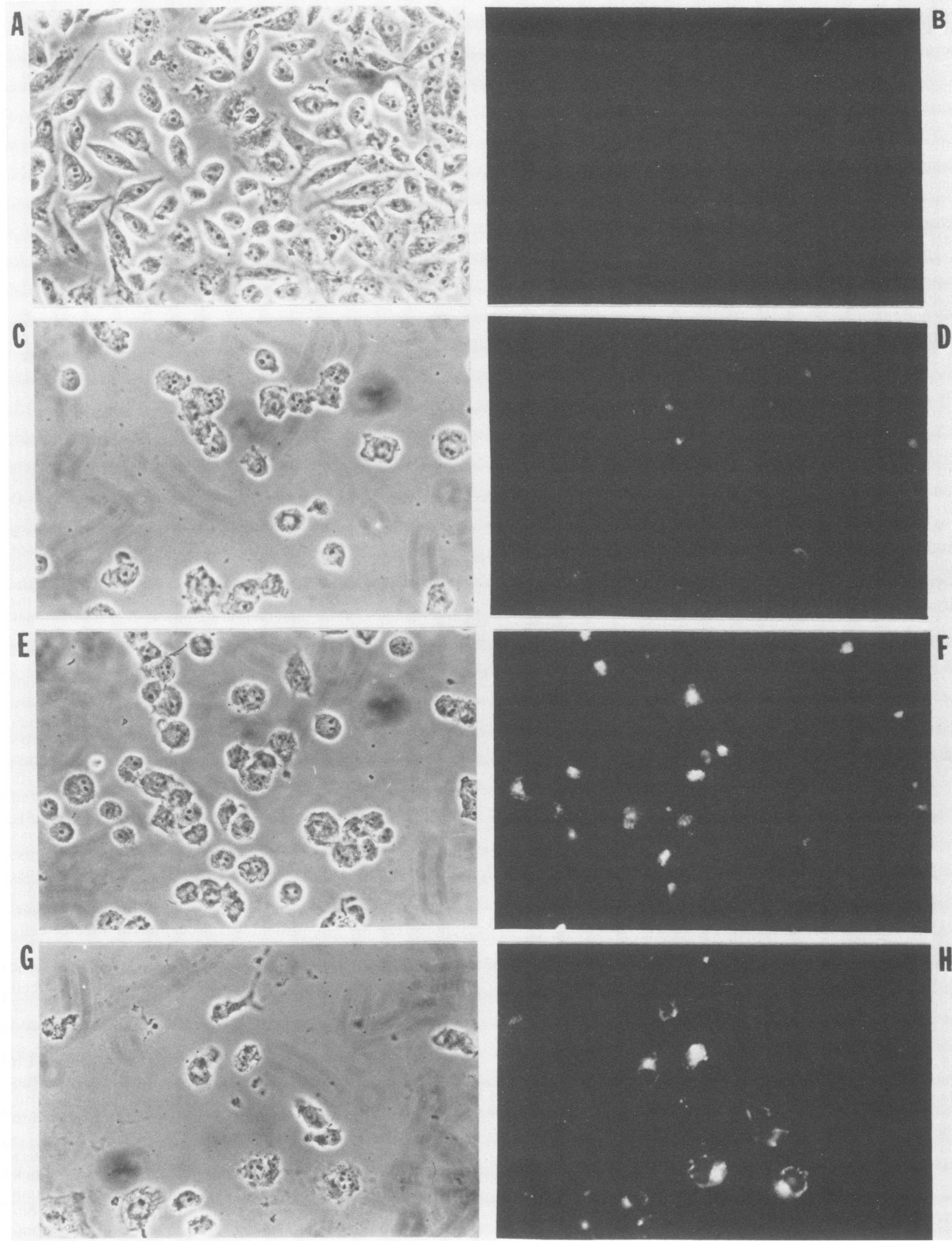


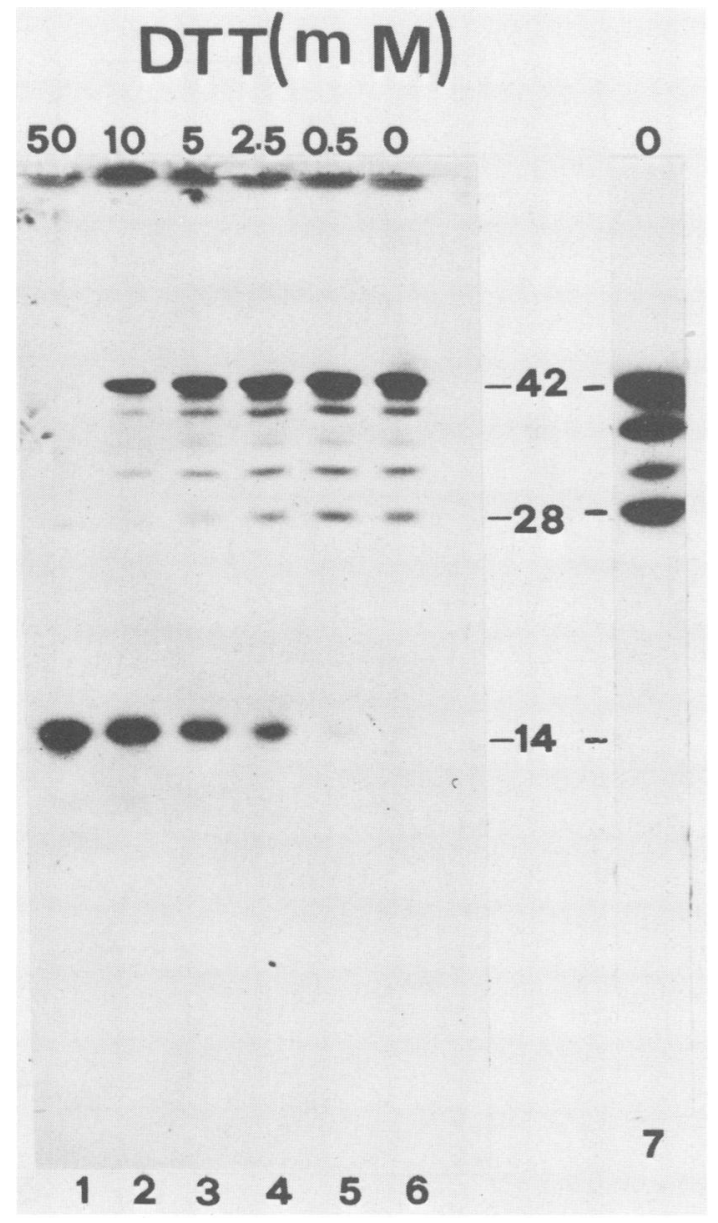

FIG. 6. The $14 \mathrm{~K}$ envelope protein of vaccinia virus forms aggregates in virions and infected cells as revealed by one-dimensional SDS-polyacrylamide gel electrophoretic analysis. Lysates of purified virus or extracts from infected cells were boiled in sample buffer in the absence or presence of increasing concentrations of DTT as described in Material and Methods. The denatured proteins were fractionated on $12 \%$ polyacrylamide gels, blotted on filters, and reacted with $\mathrm{MAbC} 3$, and the $14 \mathrm{~K}$ protein was visualized by immunoperoxidase staining (lanes 1 to 6) or ${ }^{125}$ I-protein A (lane 7). Purified virus treated with various concentrations of DTT was in lanes 1 to 6 . Cell extracts derived from vaccinia virus-infected cells in the presence of rifampin for $24 \mathrm{~h}$ (as for Fig. 3) and not treated with the reducing agent were in lane 7 . Molecular masses are in kilodaltons, and the different concentrations (mM) of DTT used are indicated.

number of vaccinia virus structural proteins are found as aggregates held by disulfide bonds (12), we examined whether the $14 \mathrm{~K}$ protein can form covalently bound aggregates both in the surface of the virion and in infected cells. Purified virions were disrupted in the presence of increasing concentrations of DTT, and the immunoblot was reacted with MAbC3. The results are shown in Fig. 6. In the absence of the reducing agent, a prominent immunoreactive band of about $42 \mathrm{~K}$ was found. With increasing concentrations of DTT, there was accumulation of the $14 \mathrm{~K}$ band. Another band of about $28 \mathrm{~K}$, but in a lesser amount than the $42 \mathrm{~K}$ band, was also found under nonreducing conditions and was gradually lost as the DTT was increased. Other minor immunoreactive proteins were also found. From the molecular weight calibration, these findings suggested that the $42 \mathrm{~K}$ and $28 \mathrm{~K}$ proteins are trimer and dimer forms, respectively, of the $14 \mathrm{~K}$ protein. The $14 \mathrm{~K}$ protein may also be associated with other virion proteins, as indicated by the appearance of immunoreactive products between the dimer and trimer. The trimer represents the major form of the $14 \mathrm{~K}$ envelope protein of vaccinia virus.

The state of the $14 \mathrm{~K}$ protein under nonreducing conditions was also investigated in virus-infected cells. A similar pattern of trimer and dimer as in the virion was obtained in cell extracts from virus-infected cells when virus maturation was inhibited with rifampin (Fig. 6, lane 7).

To document that the $14 \mathrm{~K}$ protein was indeed found associated covalently in trimers and this form was not the result of aggregation to other proteins, we carried out immunoblot analysis of two-dimensional SDS-polyacrylamide gel electrophoresis with purified ${ }^{35} \mathrm{~S}$-labeled virus. Thus, we ran the first dimension under nonreducing conditions (as in Fig. 6) while the second dimension was run under standard conditions. The immunoblots were reacted with MAbC 3 to visualize the $14 \mathrm{~K}$ protein, and the same blot was also exposed to X-ray film to visualize the labeled virionassociated polypeptides. The results are shown in Fig. 7. From the autoradiogram it is evident that a number of virion proteins form aggregates under nonreducing conditions (Fig. 7B). Among these aggregates, there is a $14 \mathrm{~K}$ protein that forms trimer, dimer, and monomer (denoted by arrows) molecules. However, these aggregates were not observed when the proteins were analyzed under reducing conditions; hence, these forms are held covalently by disulfide linkages (Fig. 7A). To prove that these forms represent the $14 \mathrm{~K}$ protein, the same blots were reacted with MAbC3 and the immunoreactive bands were superimposed with the bands in the autoradiogram. As expected, under nonreducing conditions, the $14 \mathrm{~K}$ protein was found largely as a trimer (Fig. 7D), whereas it appeared as a single polypeptide under reducing conditions (Fig. $7 \mathrm{C}$ ).

From the results of Fig. 6 and 7, we concluded that the $14 \mathrm{~K}$ envelope protein of vaccinia virus is synthesized as a single polypeptide that is subsequently associated covalently by disulfide bonds to form trimers. These trimers are found both in the surface of the virion and in infected cells.

\section{DISCUSSION}

In this investigation, we identified a novel vaccinia virus structural protein that is involved in cell fusion, and we also defined a number of biological properties of this protein with a significant role in virus-host cell interactions. By using MAbs reactive against structural proteins of vaccinia virus, we demonstrated that a $14 \mathrm{~K}$ envelope protein is involved in virus-induced cell fusion. We found one MAb, MAbC3, that reacted strongly with the $14 \mathrm{~K}$ protein and completely inhibited virus-induced cell fusion (Fig. 1 and 2). This MAbC3 has been previously shown not to block virus attachment but to block virus uncoating and virus infectivity (23). Because of the specificity of MAbC3, our findings suggest that the $14 \mathrm{~K}$ envelope protein is involved in virus penetration, possibly

FIG. 5. Surface expression of the $14 \mathrm{~K}$ envelope protein in vaccinia virus-infected cells. Mouse L cells grown in cover slips were infected with 5 PFU of wild-type vaccinia virus per cell. At various times postinfection, cells were fixed under nonpermeabilizing conditions, reacted with $\mathrm{MAbC} 3$, and processed for indirect immunofluorescence analysis. Phase-constrast and fluorescent images of the same cells are shown. Uninfected cells (panels A and B) and infected cells at $4 \mathrm{~h}$ (panels $\mathrm{C}$ and D), $8 \mathrm{~h}$ (panels E and F), and $24 \mathrm{~h}$ (panels $\mathrm{G}$ and $\mathrm{H}$ ) postinfection. 


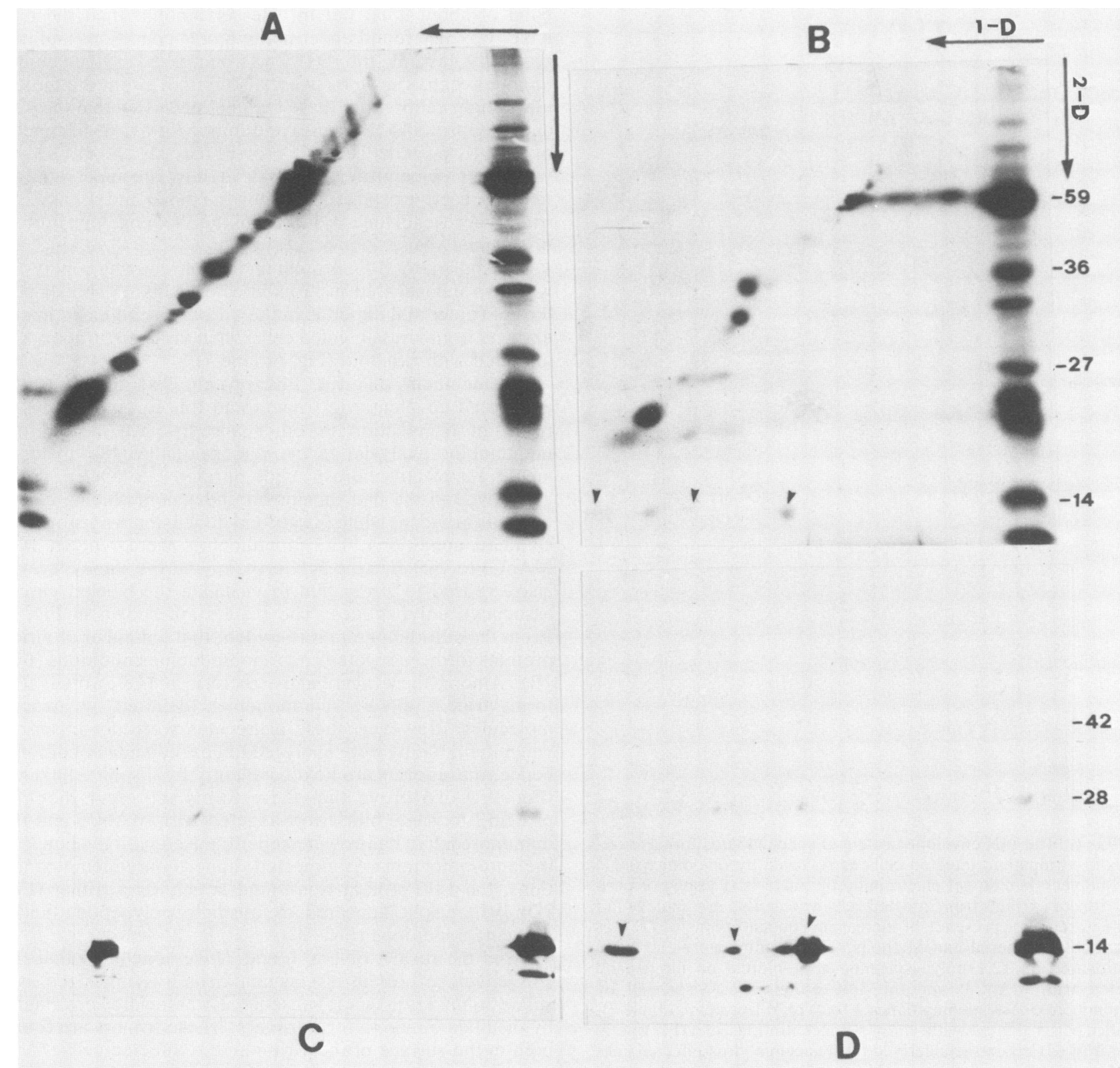

FIG. 7. Aggregates of the $14 \mathrm{~K}$ envelope protein of vaccinia virus are due to formation of trimers, as revealed by two-dimensional SDS-polyacrylamide gel electrophoretic analysis. $\left.{ }^{35} \mathrm{~S}\right]$ methionine-labeled, purified vaccinia virus $\left(40 \mu \mathrm{g} ; \mathrm{specific}\right.$ activity, $\left.2 \times 10^{4} \mathrm{cpm} / \mu \mathrm{g}\right)$ was lysed in the absence or presence of $50 \mathrm{mM}$ DTT. The denatured proteins were fractionated first on a $12 \%$ polyacrylamide gel. The corresponding lanes were cut from the gel and incubated for $30 \mathrm{~min}$ in sample buffer with DTT but without bromophenol blue, the gel was placed horizontally on top of another $12 \%$ polyacrylamide gel, and proteins were fractionated by size. The gels were blotted and reacted with $\mathrm{MAbC} 3$, and migration of the $14 \mathrm{~K}$ protein was revealed by immunoperoxidase staining. The same filters were also exposed to XAR-5 film for autoradiography. The two-dimensional gels shown in the figure represent (i) autoradiogram of virion proteins run in the first dimension (1-D) under nonreducing (panel B) or reducing (panel A) conditions and (ii) immunoblots of the virion proteins run in the first dimension under nonreducing (panel D) or (panel C) reducing conditions. Arrows point out the migration of the trimer (42K), dimer (28K), and monomer (14K). Proteins in the $11 \mathrm{~K}$ region appeared to result from proteolytic cleavage of the $14 \mathrm{~K}$ protein (23). A lane to the right in each panel represents purified virus which was run in one dimension under reducing conditions and served as markers for the second dimension. The first (1-D) and second (2-D) directions for electrophoresis are indicated.

acting at a step subsequent to virus attachment, i.e., in cell fusion. We also found another MAb, MAbB11, that could also inhibit virus-induced cell fusion but to a lesser extent than MAbC3 (Fig. 1a). This is in line with lower inhibition of virus uncoating and infectivity by MAbB11 as opposed to MAbC3 (23). Significantly, another MAb, MAbF11, that also reacted strongly with the $14 \mathrm{~K}$ protein (23), did not prevent virus-induced cell fusion (Fig. 1b). Since MAbF11 is an immunoglobulin $M$, it excludes the possibility that suppression of cell-cell fusion could be due to the adsorbed MAbs producing a steric hindrance. By indirect immunofluorescence staining and immunoblot analysis, we also showed that the $14 \mathrm{~K}$ protein is synthesized at late times postinfection and transported to the cell surface, and the monomer is 
associated covalently by disulfide bonds to make trimers in the virion and in infected cells (Fig. 6 and 7). From the kinetics of synthesis of the $14 \mathrm{~K}$ protein, we found a burst of synthesis at about $7 \mathrm{~h}$ postinfection. At the multiplicity of infection used, viral DNA synthesis began at about $1.5 \mathrm{~h}$ and peaked between 3 to $4 \mathrm{~h}$ postinfection. Since, by definition, transcription of late genes begins after viral DNA replication, we concluded that the gene encoding the $14 \mathrm{~K}$ protein belongs to a late class of viral genes. After the protein is synthesized, it is transported to the cell surace. The occurrence of cell fusion coincided with the onset of $14 \mathrm{~K}$ protein synthesis, and this event was completely blocked by two MAbs reactive against the $14 \mathrm{~K}$ protein. The possibility that membrane staining is the result of mature virus particles that are released from infected cells and become cell associated was ruled out by the facts that (i) rifampin blocked virus maturation and (ii) specific cell surface staining was observed in drug-treated, infected cells (Fig. 3). Specific cell surface staining caused by leakage of the cell membrane was also ruled out since there was no cell surface staining in infected cells reacted with an MAb that recognizes a core protein. In addition, we have previously shown that leakage of the cell surface is an early event during vaccinia virus infection, and this is followed up by rapid membrane resealing (4).

Little is known about the mode of penetration of vaccinia virus into cells. Earlier studies based on electron microscopy suggested that vaccinia virus obtains entry to the host cytoplasm by direct fusion with the plasma membrane $(1,5)$. More recently, through lysosomotropic agents and subcellular fractionation studies, we have found that fusion of the virus with the plasma membrane might play a major role in virus penetration since, soon after virus infection, the bulk of virion polypeptides is found associated with the plasma membrane (Janeczko et al., in press). A $37 \mathrm{~K}$ glycoprotein and an unidentified penetration protein have been suggested to be involved in virus attachment and penetration (11). A possible role of a $54 \mathrm{~K}$ surface tubule protein has also been proposed in vaccinia virus-induced cell fusion during the initial phases of virus penetration (25). More recently, an epidermal growth factor receptor has been implicated in vaccinia virus penetration (7). These previous studies suggested that vaccinia virus attachment and penetration are dissociated as separate events in what is apparently a multistep process. The nature and biological properties of the $14 \mathrm{~K}$ protein that we described earlier (23) and in this report suggests that this protein plays a major role in virus penetration. The evidence is as follows. (i) We have shown that MAbC3, specific against the $14 \mathrm{~K}$ envelope protein of vaccinia virus, blocks virus uncoating but not virus attachment to cells (23). (ii) MAbC3 completely inhibits virusinduced cell fusion, and this event correlates with the synthesis and transport of the $14 \mathrm{~K}$ protein from the cytoplasm to the cell surface (Fig. 1 to 5). (iii) The $14 \mathrm{~K}$ protein forms trimers which are covalently bound by disulfide linkages in the envelope of the virus and are produced during infection (Fig. 6 and 7). (iv) The 14K protein elicits neutralizing antibodies (23). The biological properties of the $14 \mathrm{~K}$ protein mentioned above would be compatible with those of a fusion protein with a role in penetration. For example, in the case of influenza virus, entry into cells is by endocytosis; the fusion protein lies on the hemagglutinin which forms trimers on the surface of membranes, and neutralizing antibodies that inhibit fusion activity are all directed at the hemagglutinin (27).

Two cell fusion events have been described in vaccinia virus-infected cells, fusion from without and fusion from within. The first refers to fusion caused by a component of the virus particle, whereas the second refers to a virusinduced product synthesized in the course of virus infection (2). Viral proteins that have been previously identified with those two functions are a $54 \mathrm{~K}$ surface tubule protein and an $85 \mathrm{~K}$ hemagglutinin $(24,25)$. The $85 \mathrm{~K}$ polypeptide is found largely in the envelope of extracellular virus (22). We demonstrated in this study that the $14 \mathrm{~K}$ protein causes fusion from within because it is synthesized at late times postinfection. However, fusion from without can also be observed with time in cells infected at high multiplicity in the presence of cycloheximide, and this phenomenon is inhibited by MAbC3 (unpublished data). Thus, our data indicated that the $14 \mathrm{~K}$ envelope protein plays a major role in cell fusion.

Expression of the $14 \mathrm{~K}$ protein at the cell surface might also play an important role in humoral immunity because this protein elicits neutralizing antibodies (23). Moreover, it may also participate in cell-mediated immune responses. Indeed, evidence has been provided that low-molecular-weight $(16 \mathrm{~K}$ to $17 \mathrm{~K}$ ) virion-derived antigens, as well as antigens expressed on the cell surface after infection, may participate in the formation of target-antigen complexes which render vaccinia virus-infected cells susceptible to recognition and killing by syngeneic, vaccinia virus-specific, cytotoxic $\mathrm{T}$ cells $(16,17)$.

Vaccinia virus is now sought as a possible universal vaccine against a broad spectrum of diseases of human and veterinary importance. This potential exists because foreign genes can easily be introduced into the viral genome and efficiently expressed during infection $(15,21)$. In view of the possible use of vaccinia virus as an agent to vaccinate humans and of the complications that have been found in the past with the practice of vaccination (14), it becomes important to characterize vaccinia virus proteins involved in virus penetration. Identification of the $14 \mathrm{~K}$ protein as a virusinduced cell fusion protein represents significant progress in this direction. Through DNA sequence analysis of the gene encoding the $14 \mathrm{~K}$ protein together with marker rescue experiments, we will be able to identify the structure of this envelope protein and its role in virus replication and virushost cell interactions.

\section{ACKNOWLEDGMENTS}

We thank George Ojakian for helpful discussions and generously allowing us unlimited use of his Zeiss fluorescence microscope and Victoria Jimenez for her skilled technical assistance.

J.F.R. and E.P. were recipients of CSIC fellowships from Spain. This investigation was supported by Public Health Service grant AI 16780 from the National Institutes of Health.

\section{LITERATURE CITED}

1. Armstrong, J. A., D. H. Metz, and M. R. Young. 1973. The mode of entry of vaccinia virus into L cells. J. Gen. Virol. 21:533-537.

2. Bablanian, R. 1974. Poxvirus cytopathogenicity: effects on cellular macromolecular synthesis, p. 391-429. In H. FraenkelConrat and R. R. Wagner (ed.), Comprehensive virology, vol. 19. Plenum Publishing Corp., New York.

3. Carrasco, L., and R. Bravo. 1986. Specific proteins synthesized during the viral lytic cycle in vaccinia virus-infected HeLa cells: analysis by high-resolution, two-dimensional gel electrophoresis. J. Virol. 58:569-577.

4. Carrasco, L., and M. Esteban. 1982. Modification of membrane permeability in vaccinia virus-infected cells. Virology 117:6269.

5. Chang, A., and D. H. Metz. 1976. Further investigations on the 
mode of entry of vaccinia virus into cells. J. Gen. Virol. 32:275-282.

6. Dales, S., and B. G. T. Pogo. 1981. Biology of poxviruses. In D. W. Kingsbury and H. zur Hausen (ed.), Virology monographs, vol. 18. Springer-Verlag, New York.

7. Epstein, D., Y. V. Marsh, A. B. Schreiber, S. R. Newman, G. J. Todaro, and J. J. Nestor, Jr. 1985. Epidermal growth factor receptor occupancy inhibits vaccinia virus infection. Nature (London) 318:663-665.

8. Essani, K., and S. Dales. 1979. Biogenesis of vaccinia: evidence for more than 100 polypeptides. Virology 95:385-394.

9. Esteban, M. 1984. Defective vaccinia virus particles in interferon-treated, infected cells. Virology 133:220-227.

10. Grimley, P. M., E. N. Rosenblum, S. J. Mims, and B. Moss. 1970 . Interruption by rifampin of an early stage in vaccinia virus morphogenesis: accumulation of membranes which are precursors of virus envelopes. J. Virol. 6:519-533.

11. Ichihashi, Y., and M. Oie. 1980. Adsorption and penetration of the trypsinized vaccinia virion. Virology 101:50-60.

12. Ichihashi, Y., and M. Oie. 1982. Proteolytic activation of vaccinia virus for penetration phase of infection. Virology 116:297-305.

13. Joklik, W. K. 1962. Purification of four strains of poxvirus. Virology 18:9-18.

14. Lane, J. M., F. L. Ruben, J. M. Neff, and J. D. Millar. 1969. Complications of smallpox vaccination, 1968. National surveillance in the United States. N. Engl. J. Med. 281:1201-1208.

15. Mackett, M., G. L. Smith, and B. Moss. 1982. Vaccinia virus: a selectable eukaryotic cloning vector. Proc. Natl. Acad. Sci. USA 79:7415-7419.

16. Mallon, R. V., E. A. Domber, and J. A. Holowczak. 1985. Vaccinia virus proteins on the plasma membranes of infected cells. II. Expression of viral antigens and killing of infected cells by vaccinia virus-specific cytotoxic T cells. Virology 145:1-23.
17. Mallon, R. V., and J. A. Holowczak. 1985. Vaccinia virus antigens on the plasma membrane of infected cells. I. Viral antigens transferred from infecting virus particles and synthesized after infection. Virology 141:210-220.

18. Nagayama, A., B. G. T. Pogo, and S. Dales. 1970. Biogenesis of vaccinia: separation of early stages from maturation by means of rifampicin. Virology 40:1039-1051.

19. Paez, E., S. Dallo, and M. Esteban. 1985. Generation of a dominant 8-Mda deletion at the left terminus of vaccinia virus DNA. Proc. Natl. Acad. Sci. USA 82:3365-3369.

20. Paez, E., and M. Esteban. 1985. Interferon prevents the generation of spontaneous deletions at the left terminus of vaccinia virus DNA. J. Virol. 56:75-84.

21. Panicali, D., and E. Paoletti. 1982. Construction of poxviruses as cloning vectors: insertion of the thymidine kinase from herpes simplex virus into the DNA of infectious vaccinia virus. Proc. Natl. Acad. Sci. USA 79:4927-4931.

22. Payne, L. G. 1979. Identification of the vaccinia hemagglutinin polypeptide from a cell system yielding large amounts of extracellular enveloped virus. J. Virol. 31:147-155.

23. Rodriguez, J. F., R. Janeczko, and M. Esteban. 1985. Isolation and characterization of neutralizing monoclonal antibodies to vaccinia virus. J. Virol. 56:482-488.

24. Shida, H., and S. Dales. 1982. Biogenesis of vaccinia: carbohydrates of the hemagglutinin molecule. Virology 111:56-72.

25. Stern, W., and S. Dales. 1976. Biogenesis of vaccinia: isolation and characterization of a surface component that elicits antibody suppressing infectivity and cell-cell fusion. Virology 75:232-241.

26. Stroobant, P., A. Rice, W. J. Gullick, D. J. Chang, I. M. Kerr, and M. D. Waterfield. 1985. Purification and characterization of vaccinia virus growth factor. Cell 42:383-393.

27. Wiley, D. C. 1985 . Viral membranes, p. 45-67. In B. N. Fields (ed.), Virology. Raven Press, New York. 